\title{
GÊNEROS DISCURSIVO-TEXTUAIS E GRAMÁTICA: PEDRAS NO CAMINHO DO PROFESSOR DE PORTUGUÊS?
}

\author{
Karen Correia* \\ Cláudio Márcio do Carmo**
}

RESUMO: Este artigo discute alguns aspectos da representação do professor de português da escola básica frente às responsabilidades que lhe são atribuídas socialmente a partir da Análise do Discurso proposta por James Paul Gee. Ele se baseia na análise de entrevistas semiestruturadas de professores de português atuantes e de alunos de um curso de Letras quanto à problemática envolvida com esse tema. Conclui que, à esteira das dificuldades inerentes à atuação profissional e a teorias aprendidas, há uma distância considerável que ora pende a uma tensão do discurso acadêmico, ora o traz como essencial, ora demonstra certo despreparo em lidar com a diferença entre a prática docente e o universo especializado que conduz grande parte do fazer docente, numa conexão estreita com as reponsabilidades que a sociedade atribui a esse importante ator no interior da instituição escolar.

PALAVRAS-CHAVE: Análise do discurso; Professor de português; Responsabilidade social.

\section{Introdução}

Não é difícil, para quem é da área de Letras, pensar em autores de grande destaque que falam sobre o casamento entre gêneros discursivo-textuais e ensino gramatical e do quanto isso otimiza o trabalho com a língua. Irandé Antunes traz uma série de contribuições nesse sentido, inclusive com títulos bastante sugestivos, mostrando o quanto a gramática, por muitas vezes, é "pedra no caminho" (ANTUNES, 2007) do professor, pois é "tudo ou nada" (ANTUNES, 2002) no ensino de Língua Portuguesa. Possenti (1996), Costa Val (2002), Perini (2003) e todos os outros autores que se dedicam a pesquisas sobre o ensino significativo de Língua Portuguesa também se debruçam sobre a questão. Nesse cenário, a centralidade da gramática tradicional é repensada e as atividades estruturais dão lugar a um trabalho contextualizado, o qual abarca o funcionamento da língua nos textos produzidos durante a interação verbal.

\footnotetext{
${ }^{*}$ Mestre em Letras pela Universidade Federal de São João del-Rei (UFSJ).

** Professor Associado do Departamento de Letras da Universidade Federal de São João del-Rei (UFSJ/CNPq). Doutor em Linguística Aplicada pela Universidade Federal de Minas Gerais (UFMG).
} 
Pelo que foi dito, parece haver um panorama positivo no contexto educacional: o ensino de língua materna vem demonstrando avanços. No entanto, o quadro descrito acima não corresponde ao que tem sido observado no ensino básico. Por isso, muitas pesquisas têm sido desenvolvidas para que as causas da distância entre os estudos desenvolvidos na academia e o ensino de línguas na escola sejam compreendidas. Essa lacuna entre o que se diz e o que faz explica que um dos grandes eixos da Linguística Aplicada seja a formação de professores de língua materna e estrangeira (MOITA LOPES, 1996).

Foi com base nessa problemática que desenvolvemos a pesquisa ${ }^{1}$ da qual este artigo é um desdobramento. O objetivo era analisar comparativamente os discursos de professores e futuros professores de português a respeito das responsabilidades sociais que lhes são atribuídas atualmente, vislumbrando entender o que tais discursos dizem sobre a relação entre teoria e prática.

Para a reflexão que pretendemos empreender, dividimos o texto em quatro seções assim dispostas: (1) Análise do Discurso - um enforque em James Paul Gee, em que apresentamos os principais pontos teóricos e princípios metodológicos utilizados; (2) Responsabilidades sociais do professor de Português, em que discorremos sobre o que socialmente é atribuído como papel do professor de Português e impacta em suas escolhas e prática docente; (3) A relação teoria/prática, em que prosseguimos com a discussão, mas focalizando a relação teoria e prática com seu impacto na atuação docente e averiguação dos construtos por ele usados em sala de aula; e (4) Gêneros e/ ou gramática: o que dizem professores e futuros professores?, seção na qual trazemos um retrato da análise de vinte entrevistas com professores atuantes e alunos de um curso de Letras, na busca de uma problematização identitária e da visão que possuem ou constroem sobre a responsabilidade social que lhes é atribuída no exercício da profissão.

\footnotetext{
${ }^{1}$ A dissertação "Na prática, a teoria é outra!': uma análise discursiva sobre a responsabilidade social do professor de Português da Educação Básica é fruto de pesquisa financiada pela Capes e desenvolvida no Programa de Pós-Graduação em Letras da Universidade Federal de São João del-Rei (UFSJ).
} 


\section{Análise do Discurso - um enfoque em James Paul Gee}

Como base teórica, usaremos a Análise do Discurso conforme proposta por James Paul Gee (1996, 2005, 2011), com especial atenção na noção de modelos Discursivos e na forma como percebe a(s) identidade(s) e o que a(s) circunda. E começamos com algumas observações sobre como língua será entendida em nossas discussões.

Gee (2005) estabelece a língua, sobretudo a língua em uso, como campo de estudo da Análise do Discurso, apontando para duas funções imbrincadas: “apoiar o desempenho das atividades e identidades sociais e apoiar as filiações humanas a culturas, grupos sociais e instituições”. (p. 1, tradução nossa). Esse imbricamento se dá devido à inter-relação entre culturas, grupos e instituições que formam atividades e identidades sociais; ao mesmo tempo em que, num processo recíproco, a instituição, para existir, depende dessas identidades e atividades às quais está conectada, ordenando-se e reordenando-se a partir delas.

Gee $(2005,2011)$ distingue discurso (com letra minúscula) e Discurso (com letra maiúscula). Este envolve pensar que o processo de significação que acontece entre as pessoas não abrange apenas a língua, pois aquele que toma para si o discurso comunica ao outro a quem se dirige um papel, uma identidade socialmente situada que é assumida no momento da interação, e a língua sozinha não alicerça todas essas atividades. A noção de Discurso, portanto, é mais ampla e envolve questões de representação e reconhecimento. Tem a ver com a identificação de uma pessoa como membro de um grupo, com o reconhecer-se como um tipo de pessoa. Segundo Gee (2011, p. 37, tradução nossa):

Um Discurso com 'D' maiúsculo é composto de modos distintos de falar/ouvir e muitas vezes também de escrever/ler, juntamente com formas distintas de agir, interagir, valorizar, sentir, vestir, pensar, crer, com outras pessoas e com vários objetos, ferramentas e tecnologias, de modo a representar identidades socialmente reconhecíveis.

Gee (2005) fala então em uma análise de D/discurso, demonstrando que a língua é uma dimensão importante, mas não a única que importa no momento da análise. Essa definição de Discurso se diferencia da língua, e ainda mais da língua fora do uso. Essa 
distinção está diretamente relacionada ao que o autor considera ser a teoria central da análise de discurso por ele proposta: que "a língua só tem significado em e através de práticas sociais" (GEE, 2005, p. 8), o que abarca não apenas o modo como se usa a língua, “[...] mas quem você é e o que você está fazendo quando você diz [algo]." (GEE, 1996, p. 124, grifos do autor, tradução nossa).

Tendo isso em mente, partimos do princípio que as questões que envolvem a prática docente e circundam o pensamento sobre suas reponsabilidades sociais podem sem trabalhadas nesses moldes ao envolverem diferentes representações, visões de mundo, pensamentos, crenças e identidades na dinâmica social, em especial na dinâmica que se dá no interior da instituição escolar a qual está envolta em diferentes responsabilidades que são projetadas por todos os atores envolvidos nela.

A abordagem foi qualitativa e a análise de natureza exploratória de vinte entrevistas semiestruturadas baseadas num questionário de dez perguntas ${ }^{2}$, respondido por dez professores de português atuantes na rede pública (municipal e estadual) de ensino do município de São João del-Rei, por dez graduandos do curso de Letras-Português da Universidade Federal de São João del-Rei. As perguntas foram definidas a partir dos PCNs de língua portuguesa. Tendo em vista que o documento era um dos principais norteadores do ensino, tópicos nele recorrentes e relacionados à formação para a cidadania foram selecionados e compuseram o roteiro.

\footnotetext{
${ }^{2} \mathrm{O}$ roteiro era composto pelas seguintes perguntas: (1) Qual a finalidade e a importância da aula de Português?; (2) Como você enxerga o trabalho com gêneros textuais? Por quê?; (3) Quais temas devem ser discutidos na aula de Português? Por quê?; (4) O que se espera ao trabalhar textos (leitura e escrita) em sala de aula?; (5) O que você pensa sobre a atenção à individualidade do aluno? Por quê?; (6) O que você entende por avaliação e o que deve ser avaliado?; (7) Você acha importante orientar-se por documentos como os PCNs e o CBC? As propostas do CBC e dos PCNs envolvem a participação ativa da família, dos alunos e da escola como um todo. O que você pensa sobre essa questão?; (8) Qual a distância entre o que você aprendeu/aprende na universidade e o que você faz/fará no seu trabalho? Fale um pouco mais sobre essa relação; (9) Você acredita que o professor de Português tenha responsabilidades na formação de cidadãos? Quais/Em que sentido? Há dificuldades em cumpri-las?; (10) Para você, é possível ser neutro em sua atuação docente? Como?
} 
Ao partir dos PCNs para seleção dos temas, não consideramos que o professor de educação básica esteja conseguindo cumprir tudo o que estabelece o documento. $\mathrm{O}$ discurso oficial não necessariamente representa a prática. Ainda assim, consideramos importante levá-lo em conta, pois é ele que estabelece o que há de proposta para o ensino, o que, em tese, deveria estar ocorrendo. Nesse sentido, concordamos com Freire (2013) que o discurso oficial pode ser usado por quem busca mudança para reivindicar a aproximação entre o que se diz e o que se faz.

O ponto chave para a análise exploratória das entrevistas está na identidade dos participantes e de sua visão sobre as responsabilidades sociais atribuídas aos professores de português de forma geral, a partir das nuances envolvidas nesse processo, tomando como norte o que nos explica Gee (1996, p. ix, tradução nossa) na passagem que segue:

Cada um de nós é membro de muitos Discursos, e cada Discurso representa uma de nossas múltiplas identidades. Esses Discursos não precisam - e geralmente não o fazem - representar valores consistentes e compatíveis. Existem conflitos entre eles, e cada um de nós vive e respira esses conflitos enquanto atuamos nossos vários Discursos. Para alguns, esses conflitos são mais dramáticos do que para outros. [...] Eles são o local de luta e resistência muito real.

Isso porque fazemos escolhas e suposições, as quais Gee (1996) chama de "distinções significativas", com base em crenças e valores, vistos como teorias sociais que "[...] envolvem (geralmente de forma inconsciente) suposições sobre modelos de mundos simplificados" (GEE, 1996, p. 78, tradução nossa), os modelos Discursivos referidos também como modelos culturais.

Como distinção, o autor explica que "[...] todos os modelos culturais tendem, em última análise, a limitar nossa percepção das diferenças e das novas possibilidades. Eles nos permitem funcionar no mundo com facilidade, mas ao preço de estereótipos e de pensamento e percepção rotineiros." (GEE, 1996, p. 89, tradução nossa). Certas exclusões, então, são ocasionadas pelos modelos Discursivos. É a partir deles que damos sentido aos textos e ao próprio mundo. Eles definem, por exemplo, o que é tido como central, típico, 
e o que é marginal, atípico. Logo, os modelos Discursivos desempenham um papel na criação e manutenção de estereótipos.

Gee (2005) explica que os modelos culturais são ferramentas importantes para investigação porque medeiam a interação, uma vez que podem ser vistos a partir das imagens ou descrições em que ocorrem desdobramentos de eventos prototípicos. A língua e a gramática, nesse sentido, trazem as marcas dos processos sociais envolvidos nas construções e visões de mundo das pessoas na forma das palavras utilizadas, do discurso (re)produzido e da identidade de quem as profere na qualidade de pertencente ou não a um determinado modelo cultural e grupo social.

De acordo com Gee (2005, p. 68), os modelos podem ser: (1) de apoio (espoused mo$d e l s)$, quando conscientemente conectamos um modelo a outro, com o intuito de sustentar nosso ponto de vista; (2) avaliativos (evaluative models), usados em nossos julgamentos cotidianos, sejam eles feitos de forma consciente ou não, sobre nós mesmos e sobre outrem; e (3) em interação (models-in-interaction), quando, de forma consciente ou não, forem usados para orientar nossas ações e interações no mundo. Esses modelos são, acima de tudo, entidades dinâmicas que possibilitam novos olhares sobre uma sociedade e sua cultura, eles estão sempre em interação com a sociedade e com a cultura que os utilizam e (inter)relacionam.

De forma específica, partimos então da ideia que eles são uma fonte importante para a problematização da identidade do professor e de sua visão sobre a responsabilidade social que lhes é socialmente incumbida. E uma das fontes para essa problematização está marcada nas escolhas léxico-gramaticais feitas pelos atores sociais envolvidos direta ou indiretamente com a instituição escolar, pois conforme nos esclarece Gee (2005), alguns modelos Discursivos são compartilhados entre vários Discursos diferentes, enquanto outros estão restritos a apenas um Discurso, ou a um número reduzido deles: “[...] os significados situados das palavras são conectados a diferentes modelos Discursivos, ligados a grupos sociais específicos e seus Discursos característicos” (GEE, 2005, p. 62, tradução nossa). 


\section{Responsabilidades sociais do professor de português}

Contextos e ideologias distintos implicam diferentes concepções sobre o ensino de língua materna. Assim, de tempos em tempos observamos mudanças na função da aula de português e, consequentemente, na concepção de língua que perpassa as práticas de ensino. Certamente, o papel atribuído ao professor e a representação que se tem sobre ele na sociedade também variam conforme esses fatores.

As incumbências hoje imputadas estão muito relacionadas à nova configuração global que presenciamos, a qual traz como preocupação a formação de cidadãos. Desde o surgimento dos PCNs, o discurso oficial passou a se alinhar a essa demanda, de modo a priorizar uma educação que prepare o aluno para a vida extraescolar. Para atender a tais objetivos, o professor é chamado a assumir responsabilidades sociais em relação a seus alunos, abarcando, de forma prioritária, a dimensão social do ato de ensinar.

Por responsabilidade social entendemos uma maneira de posicionar-se enquanto docente que leva em conta que o aluno possui uma vivência fora da escola, a qual tem um compromisso com esse aluno enquanto sujeito, com sua formação não apenas no que diz respeito aos conteúdos disciplinares, mas também com sua atuação no mundo. No caso específico das aulas de português, a própria maneira de lidar com o ensino da língua demonstra uma responsabilidade social. Tratá-la como de fato funciona na vida social é uma maneira de apresentar o aluno a padrões de linguagem a que ele não tinha acesso, sem desconsiderar o padrão da comunidade em que ele vive, oportunizando que a língua seja não empecilho, mas instrumento de expressão, maneira de colocar-se no mundo. Uma educação linguística ampla é condição de cidadania.

Logo, os gêneros textuais também abrangem a dimensão da responsabilidade social da qual estamos falando. Isso porque eles estão muito imbricados no cotidiano de qualquer pessoa, pois "Fruto de trabalho coletivo, os gêneros contribuem para ordenar e estabilizar as atividades comunicativas do dia-a-dia" (MARCUSCHI, 2005, p. 19). Eles perpassam a vida de todos os sujeitos e têm origem nas necessidades e nas atividades humanas. Desse 
modo, "[c]aracterizam-se muito mais por suas funções comunicativas, cognitivas e institucionais do que por suas peculiaridades linguísticas e estruturais” (MARCUSCHI, 2005, p. 20).

A própria definição de gêneros trazida por Marcuschi (2005) demonstra a sua relação com o aspecto social e cultural, o que envolve, inevitavelmente, a questão da cidadania em seu sentido mais amplo, já que os gêneros são formas de ação social e são realizados em contextos específicos. Voltando-se diretamente para o trabalho com textos no ensino, Marcuschi (2005) considera que tanto a produção quanto a compreensão podem melhorar a partir do conhecimento de um número variado de gêneros e seus funcionamentos, já que todo texto materializa um gênero. Antunes (2009, p. 50-51) explica essa questão quando mostra uma mudança de paradigma no trabalho com a leitura e a escrita, indo das frases soltas para os textos:

As definições e classificações categóricas, que são possíveis no âmbito da palavra e da frase isoladas, foram dando lugar às dependências enunciativas e contextuais. Nessa perspectiva, as palavras e as frases passaram a ganhar pleno sentido na medida em que são vistas como partes de textos, como componentes de discursos, pelos quais as pessoas dizem, agem, participam, tomam posições, se firmam e se afirmam no aqui e no agora de sua existência.

Levando-se em conta que a partir dos discursos agimos socialmente, a inserção de um sujeito que domine uma gama variada de gêneros poderá ser mais ampla e eficaz, pois, conforme Bezerra (2005), não existe sujeito iletrado, mas sujeitos que dominam diferentes níveis de letramento.

Do mesmo modo, a gramática da língua não deve deixar de ser ensinada. O que os linguistas reivindicam é que ela não seja vista como a própria língua. É muito comum nas escolas que a gramática seja vista não apenas como o todo linguístico, mas também que seja ensinada de modo prescritivo, com base em valores como certo e errado, feio e bonito. A variedade de prestígio, nesse caso, é tomada como a representante oficial da língua, e o ensino se reduz à memorização de normas. Na mesma perspectiva que defende que os gêneros sejam o centro do ensino pelo aspecto comunicativo, pela preocupação com a 
interação social, os estudiosos propõem uma gramática contextualizada, o que exige reconhecimento da relação entre texto e gramática e significa, segundo Antunes (2014, p. 141), "explorar os possíveis resultados dos usos, das escolhas, das substituições que fazemos". Para Costa Val (2002), significa falar de gramática do/no texto, mostrando como se dá tal relação não opositiva entre as duas dimensões. Diferentes gêneros usam diferentemente a língua para produzir efeitos de sentido distintos. É nesse sentido que gêneros textuais e gramática vêm sendo relacionados no ensino de português.

Dificilmente encontraremos, hoje, um professor de português que não fale em gêneros textuais, que não elenque vários deles em sua aula, até mesmo defendendo a necessidade de sua presença como tópico central do ensino de português. Também é incomum encontrarmos um que não fale em uso linguístico e em variedades linguísticas. Todavia, é necessário pensar qual a motivação para que os professores trabalhem tais tópicos, pois isso implica diretamente na forma como o ensino vem sendo desenvolvido. As entrevistas mostraram que o discurso oficial e o discurso acadêmico influenciam as ações de professores atuantes e de graduandos. Contudo, na maioria das vezes os professores não percebem tais discursos como forma de orientação, mas sim como cobrança, o que ocasiona muitos conflitos. Os efeitos desses discursos sobre os professores são muito grandes, pois são tomados como aquilo que deve ser seguido pelo bom professor. Dentre as ações consideradas obrigatórias pelos entrevistados estão o protagonismo dos gêneros textuais na aula, bem como a contextualização da gramática.

\section{A relação teoria/prática}

A mudança de prioridades no ensino e a consequente alteração na função do professor implicam também que a universidade, responsável pela formação de professores, assuma novas responsabilidades. Fazendo referência específica ao curso de Letras, o que se pretende com essa nova formação é que os futuros professores, a partir de uma formação teórica consistente, enxerguem a língua, seu objeto de trabalho mais imediato, não como gramática normativa, ou como exercício escolar, mas como uma das maneiras de levar o aluno a posicionar-se frente à realidade que o cerca, como uma possibilidade de 
estabelecer diálogo, de ler e escrever de maneira eficiente e com objetivos, como maneira de expressar opinião e ideias.

Quando dizemos que os cursos de Letras precisam oferecer embasamento teórico sólido ao aluno, não pensamos em acúmulo de informações, mas no estabelecimento de uma rede de conhecimentos que servirá de suporte para uma atuação docente consciente, reflexiva. Pensamos em um professor que não repita modelos, mas que tenha a possibilidade e capacidade de criar seus próprios métodos com base nas teorias estudadas. A teoria, aliás, precisa ser muito bem trabalhada durante a formação do professor, de forma que ele possa não decorar, mas introjetá-la como maneira de se posicionar e de agir. Concordamos com Guzzo (2011, p. 49) a esse respeito: “[i]nvestir na prática, sem a necessária valorização do saber teórico, é conduzir para a formação de um profissional preparado para a reprodução curricular e pouco afeito à construção de argumentos para criticar políticas e tomar decisões educacionais".

É importante deixarmos claro desde já que não entendemos que teoria e prática sejam dois polos que não mantêm relação; ao contrário, pensamos que são duas dimensões de um mesmo processo. Logo, deveriam caminhar juntas para que a teoria não se torne "um acúmulo de informações sem uma sistematização, que lhe fundamente as evidências colhidas numa prática refletida que tencione e recrie a teoria.”. (FERNANDES, 2011, p. 66).

No entanto, percebemos que nem sempre as duas dimensões se relacionam. É o caso das teorias que embasam os cursos de formação em Letras e a prática docente de língua portuguesa na escola. Observamos muitas críticas em relação às ações do professor de educação básica vindas, inclusive, da universidade. Nesse sentido, surgiram algumas questões: até que ponto a formação que tem sido oferecida corresponde à prática docente? O que pensa o professor de português sobre as funções que lhe são atribuídas? As teorias pedagógicas e linguísticas que embasam a formação em Letras têm partido da realidade profissional dos professores, têm levado em conta suas experiências em sala de aula, têm surgido do contato com essa prática ou de uma idealização da mesma? 
Se as teorias que vêm sendo oferecidas pelos cursos de Letras aos futuros professores não partem da observação da prática escolar, corre-se o risco de que o preparo para as responsabilidades sociais fique restrito ao âmbito teórico, o que pode ser problemático, já que haveria a cisão entre as duas dimensões de que falamos e a teoria seria vista como aquilo que se comprova na prática, ou seja, como algo que vem antes desta (FERNANDES, 2011). Visto desse modo, o conhecimento teórico acaba por se formar com base naquilo que se idealiza, e não no que acontece de fato. O problema é que possuir um saber, dominar uma teoria não significa transpor, automaticamente, para a prática. Ou, conforme Gasparini (2013, p. 56-57, grifos do autor), “assim como há diferença entre saber sobre procedimentos metodológicos e saber se apropriar deles em ato [...] o conhecimento teórico não é automaticamente transferido para um saber-fazer em sala de aula.".

Ter noção da responsabilidade social do professor enquanto graduando não é, necessariamente, assumi-las na atuação profissional. Como já dissemos anteriormente, nem sempre a prática funciona como propõem os documentos oficiais. Há uma inversão da lógica quando se cria uma teoria para ser testada na prática sem que se parta desta. No âmbito da docência, isso pode gerar frustrações, sentimento de impotência e uma falta de referência no agir docente que acaba por colocar em descrédito tudo o que se aprende na universidade, levando a um retorno ao que tradicionalmente é feito. Conforme Tardif (2000, p. 11-12),

Essa distância pode assumir diversas formas, podendo ir da ruptura à rejeição da formação teórica pelos profissionais, ou então assumir formas mais atenuadas como adaptações, transformações, seleção de certos conhecimentos universitários a fim de incorporá-los à prática. Desse ponto de vista, a prática profissional nunca é um espaço de aplicação dos conhecimentos universitários. Ela é, na melhor das hipóteses, um processo de filtração que os dilui e os transforma em função das exigências do trabalho; ela é, na pior das hipóteses, um muro contra o qual se vêm jogar e morrer conhecimentos universitários considerados inúteis, sem relação com a realidade do trabalho docente diário nem com os contextos concretos de exercício da função docente.

Essa rejeição à teoria tem a ver com a característica dos saberes profissionais do professor, que são múltiplos e podem, muitas vezes, parecer incoerentes ao olhar científico 
na maneira como são mobilizados na prática. O professor não precisa lidar, apenas, com o ensino de um conteúdo. É preciso cuidar da motivação e concentração dos alunos, da integração do grupo, de questões individuais de aprendizagem, já que não existe homogeneidade em uma turma, trabalhar questões que sejam relevantes socialmente e cumprir um cronograma curricular que é imposto, dentre tantos outros objetivos. Nesse cenário, os saberes profissionais estão a serviço da ação, do modo mais eficaz de se atingir objetivos, que são muitos e simultâneos.

À universidade caberia, portanto, uma formação ampla, que abarcasse diversas competências. Contudo, temos presenciado um conhecimento universitário aplicacionista (TARDIF, 2000), baseado em uma divisão entre pesquisa, formação e prática, de modo que os pesquisadores produzem conhecimentos para serem transmitidos na formação dos universitários; estes, depois, aplicarão os conhecimentos em sua prática. Esse modelo, no entanto, é idealizado com base em uma lógica disciplinar, e não profissional. Logo, não leva em consideração a realidade do trabalho dos professores, o que gera grandes impasses. Ao analisar revistas especializadas sobre o ensino de línguas, Coracini (2003) chega à conclusão de que os especialistas são considerados autoridade pelos professores e por eles mesmos no que concerne às decisões que devem ser tomadas no ensino. Isso faz com que os especialistas assumam a postura do aconselhamento, da recomendação.

As análises das entrevistas mostraram a mesma realidade: o discurso acadêmico, legitimado pela fala de especialistas, tem o mesmo peso que as diretrizes oficiais. Assim, impõe o que deve ser feito em sala de aula, gerando sobrecarga no professor e no futuro professor. Sobre esse aspecto, convém comentarmos sobre o papel do intelectual. Ele é capaz de fazer com que um grupo saiba melhor aquilo que já sabia quando organiza o conhecimento, assim como pode cessar a curiosidade das pessoas quando decide pelo grupo os conteúdos que ele precisa saber, sem que se parta dos conhecimentos que ele já possui. (FREIRE; NOGUEIRA, 2011). Nesse caso, o conhecimento é transformado em conceitos, e o professor deixa de questionar a ordem que está posta. Assim, o conhecimento não se movimenta, não é criado, mas engessado em frases feitas. O professor é, então, desapossado de seu saber. 
Assim sendo, a universidade deixa de funcionar como espaço de construção do conhecimento, pois já vem pronto para ser transmitido aos alunos. Sua legitimidade produz a ideia de que os professores de educação básica precisam seguir aquilo que é dito pelos intelectuais em teorias relacionadas à educação, pois eles dominam um conhecimento que que é essencial para facilitar e melhorar a prática docente na escola.

Essa discussão nos coloca diante de um grande problema: por um lado, espera-se que os professores mobilizem os saberes adquiridos ao longo da graduação para resolverem, de maneira autônoma, os problemas encontrados na sala de aula. Mas a maneira como a universidade tem lidado com o saber teórico não é justamente contrário ao desenvolvimento da autonomia? A visão aplicacionista coloca sempre o risco de uma educação bancária (FREIRE, 1997), em que o saber de quem sabe é depositado na cabeça dos que precisam aprender. Se o conhecimento precisa apenas ser aplicado, o professor torna-se passivo, um aplicador de modelos que deixa de lado a sua criatividade para tentar se adequar ao ideal de bom professor. Nesse aspecto, concordamos que é preciso um resgate social da profissão docente, de modo que o próprio professor reflita sobre sua função, sem que outras pessoas façam isso por ele de maneira prescritiva (NÓVOA, 1999).

\section{Gêneros e/ou gramática: o que dizem professores e futuros professores?}

Tendo em vista as responsabilidades que são atribuídas aos professores e as discussões tão frequentes sobre a relação entre teoria e prática, investigamos como os professores e futuros professores de português criam identidades para si frente a essas funções e como o cumprimento ou não de tais responsabilidades tem relação com um impasse entre teoria e prática docentes. Partimos das falas dos próprios professores e futuros professores de língua portuguesa para entender tais questões. Vários temas foram abordados nas entrevistas, mas consideramos que alguns deles são mais representativos da visão que os entrevistados têm sobre a relação teoria/prática, como é o caso dos gêneros textuais e da gramática da língua. Tais tópicos são muito significativos, pois demonstram que a incompreensão teórica leva a discursos contraditórios e conflituosos. 
No roteiro de entrevistas havia pergunta sobre os gêneros textuais e sobre leitura e escrita nas aulas de português. De um modo geral, o trabalho com o texto é muito relacionado pelos professores à vida extraescolar. Isso pode ser notado, por exemplo, na fala da professora Thaiana ${ }^{3}$, quando questionada sobre o trabalho com os gêneros textuais:

é eu acho que ... deveria ser o foco do currículo e infelizmente não é ... né? o nosso currículo ainda é muito preso no ... nas questões estruturais da gramática ... agora como ele é trabalhado ... né? ... eu acho que ... bom ... a importância é que não tem como a gente trabalhar ... interpretação e leitura ... e produção de textos sem focar nisso ... né? ... e segundo ... que ... quando a gente ... aborda com um pouco mais de profundidade ... às vezes até trazendo mais materiais do que o próprio livro didático traz ... o que eu sinto muitas vezes é que é um tipo de material que mais chega perto dos alunos ... que talvez às vezes faz mais parte do cotidiano deles. ${ }^{4}$

O trabalho gramatical, tão conflituoso nos discursos dos entrevistados, demonstra os problemas gerados quando a teoria é seguida, mas não compreendida. Ao tentarem se alinhar aos discursos oficial e acadêmico, muitos entrevistados acreditam que precisam extinguir a gramática de suas aulas, ao mesmo tempo em que não conseguem fazer isso, retomando o tópico gramatical a todo instante. Nathália demonstra o trabalho com os gêneros por obrigatoriedade:

e eu trabalho os gênero textuais com eles ... mesmo porque ... é o nosso programa ele orienta todo o nosso CBC é todo a base nos gêneros textuais ... né? ele quase não trabalha a parte gramatical ... embora eu ainda ache ele meio falho.

Ainda que nenhuma das perguntas mencionasse a gramática tradicional, ela foi citada por muitos entrevistados, normalmente em oposição ao trabalho textual, como se pode notar, fazendo-se presente numa tentativa de afirmação de sua pouca utilidade. Nessa tentativa incessante de retirada da gramática sem entender o que de fato se propõe e o sentido da proposição, os professores e mesmo os graduandos constituem suas identidades docentes com base em um conflito, muitas vezes mantendo um trabalho tradicional, pouco

\footnotetext{
${ }^{3}$ Todos os nomes de entrevistados são fictícios.

${ }_{4}$ Todas as falas dos entrevistados constituem o corpus da pesquisa já mencionada e podem ser acessadas na íntegra por meio do seguinte link: https://ufsj.edu.br/portal2-repositorio/File/mestletras/Quadros\%20PDF$\% 20$ anexo $\% 20$ karen.pdf.
} 
significativo, mas acreditando ter mudado a forma de trabalhar ou, em outros casos, frustrando-se por não conseguirem fazer o que acreditam ser proposto.

Da mesma forma, os gêneros são, muitas vezes, valorizados sem que se entenda a real importância de planejar aulas que partam deles. Nesses casos, nomenclaturas são o foco do trabalho desenvolvido: a identificação de gêneros e tipos textuais com o mero objetivo de classificá-los, deixando de lado as funções comunicativas e a relação com a interação social, como pode ser visto na fala da professora Nathália: "trabalho muito isso com eles ... é ... trabalho a tipologia ... porque às vezes o aluno confunde o que é tipologia e gênero ... chega um ponto que eu já vou perguntando ... que gênero é esse? eles já vão identificando". Casos como o mencionado demonstram que alguns professores que trabalham apenas a identificação conhecem bem o conceito, o que atesta que dominar uma teoria não significa entender sua importância e desenvolver um trabalho significativo na prática, de forma que há valorização do tópico no discurso, mas não no Discurso.

Por outro lado, percebemos que pequenas confusões conceituais não atrapalham o desenvolvimento de um trabalho significativo quando a real importância do tópico é compreendida, quando a teoria foi introjetada. Para Manuela, por exemplo, uma das graduandas entrevistadas, a função do professor de LP está muito relacionada ao trabalho com os gêneros, pela função social que estes desempenham, por serem recorrentes na vida cotidiana dos alunos. Apesar de mostrar a eficácia disso e a importância desse tipo de trabalho, a graduanda faz confusão entre os conceitos de gêneros e de suporte, tratando a televisão como um gênero textual.

eu também acho de suma importância ((risos)) ... porque igual eu di/eu disse ... tudo que o aluno olha fora da escola ... é gênero ... todo $\mathrm{v} /$ por exemplo ... é ... e o gênero eles têm muito ... veículos de circulações ... então ... todo lugar ... ele vai encontrar gêneros ... e às vezes ele nem sabe que é um gênero textual ... e quando a gente leva ... o/o gênero ... que eles veem na rua pra escola ... eles ficam muito surpresos ... igual ... no PIBID a gente fez ... um ... do gênero televisão ... a gente ... fez um quadro de televisão do Jornal Hoje ... nossa para eles foram o máximo ... eles nem sabia que é/a televisão era um gênero textual ... por exemplo ... sabe? reportagem ... essas coisas ... eles ficaram mu/muito assim ... abismados.

Embora faça confusão entre conceitos, consegue desenvolver o trabalho com foco no aspecto comunicativo, de forma que os alunos se interessem pela discussão. Ela entende 
a importância real do trabalho com gêneros no ensino de língua portuguesa, enfocando suas características comunicativas, sua função social e o impacto que podem ter no cotidiano dos discentes. Isso demonstra que há um saber introjetado a respeito deste trabalho, de forma que uma confusão entre conceitos se torna pouco significativa na prática docente, já que os objetivos do que a graduanda desenvolveu nas aulas estavam claros para ela e bem definidos.

Em relação ao discurso acadêmico, identificamos alguns aspectos importantes. Com base neles, há uma postura de julgamento por parte de alguns graduandos, que não valorizam qualquer ação que fuja ao que acreditam ser adequado. Com base também nesses discursos, muitas vezes julgam os docentes, dizendo que não mudam porque se contentam com uma aula pouco significativa, já que não se preocupam em oferecer um bom ensino. A graduanda Renata se posiciona dessa maneira quando perguntamos sobre as expectativas do professor de português em relação à leitura e à escrita:

então ... às vezes pro professor é muito mais prático pegar um texto que já tá lá pronto no livro ... pegar uma questão gramatical que já vem com esse texto mesmo ... e ficar naquilo ... e não pesquisar problematizar alguma coisa que tá acontecendo.

Todavia, os Discursos dos professores demonstram exatamente o contrário: não conseguir fazer não significa falta de preocupação. Muitas vezes, eles admitem que não conseguem mudar sua forma de trabalho, mesmo percebendo ser importante, ou não têm como refletir nem mesmo sobre a necessidade de mudança, porque não conhecem ou não entendem suficientemente as novas proposições para avaliá-las e constituir uma opinião a seu respeito.

Aliás, algo que precisa ser apontado é que os próprios alunos, quando questionados a respeito de sua formação, a todo instante criticam a gramática e professores que se prendem a ela, a um ensino descontextualizado, conteudista. Todavia, quando se colocam na posição daquele que irá lecionar, quando pensam em seu futuro trabalho, retomam a gramática com muita força e passam a criticar o curso de Letras por não oferecer tantas disciplinas de gramática, que é o que será trabalhado na sala de aula. Isso demonstra que o ensino contextualizado está confinado ao espaço da idealização de um ensino. 
O discurso da graduanda Renata deixa claro o impasse entre teoria e prática. Ainda comentando sobre as expectativas do professor em relação à leitura e à escrita, ela é bastante enfática ao apontar o que professores já atuantes esperam, criticando o modo como lidam com a gramática. Por outro lado, ao falar de suas próprias expectativas, ela se alinha ao discurso acadêmico, mas diz que sua opinião é embasada em uma utopia de escola, e não na realidade, já que ela não possui experiência:

hum ele ... ((risos)) geralmente ... pelo que eu tenho observado é ver ... se o aluno tá escrevendo corretamente de acordo com gramática ... então ... ((risos)) eu ... assim ... pela experiência que eu tenho ... é ... comé que eu posso dizer? é um pouco complicado né? porque eu não tenho ... muita experiência ... eu não tenho como falar ... é ... com base na ideia ... naquela utopia da ((risos)) ... da ... da escola prefe/perfeita ... da aula perfeita assim ... a gente espera/eu espero levar ... textos que estejam coerentes à minha turma ... porque ... o que eu acho que é importante ... independentemente - acho que tudo mundo assim ... até quem não tem experiência como eu ... é ... sondar o perfil da turma ... né? ver quais são as dificuldades ... é ... quais são ... as expectativas deles também ... em relação ... ao que eles vão aprender ... eu acho que primeiro é isso ... sondar ... né?

Contudo, ao falar sobre os temas que devem ser abordados na aula de português, a graduanda retoma o embate entre gramática e gêneros. Ainda que defenda uma gramática contextualizada, o que implica a junção desses dois aspectos, ao pensar na prática Renata demonstra não saber como os dois tópicos poderiam ser conectados, chegando a afirmar que a situação aflige também outros colegas de curso, que não querem lecionar português por não saberem gramática. Ainda que critiquem a gramática descontextualizada, é esse o modelo de aula que eles têm, pois consideram que o que aprendem no curso é uma utopia:

então eu acho que ... tinha que ... ter uma maneira de ... juntar as duas coisas ... que a gen/o que a gente vê ... são essas coisas separadas ... tipo a aula de português ... tem aula de português ... de gramática ... e tem a aula de português de produção de texto ... então tinha que ter uma maneira de juntar as duas coisas pro aluno ... ele se colocar né? ... perante a língua porque ele ... fala .... ele pensa nessa língua ... então ele tem que se colocar ... ele não pode ficar só naquele estruturinha ... básica assim ... né? tipo ah aula de português é gramática ... eu acho que isso é um pouco ... chato ... por isso que ninguém se interessa pela língua que fala em português ... que nem vem na minha cabeça às vezes é gramática ((risos)) e eu tenho muitos colegas aqui na universidade que falam eu não vou ensinar ... português porque ... eu não sei ... gramática direito ... então ... num é legal ... nem pra mim ... por que eu vou ensinar? 
Os Discursos mostraram que o apego ao discurso oficial é uma tentativa de valorizar a formação que ainda estão tendo e de manter a esperança de que a ação do professor pode mudar esse cenário. Contudo, quando se imaginam professores, não conseguem pensar em uma alternativa para por no lugar. Diante da ausência de referência, se apegam ao modelo de aula de português observado enquanto alunos do ensino básico ou estagiários do curso de Letras, pois só conseguem imaginar a gramática contextualizada enquanto teoria.

Como vimos, há uma distância esperada entre prescrito e real, de forma que o primeiro serve de apoio, é lente a partir da qual se enxerga o mundo e que auxilia na tomada de decisões. A boa compreensão teórica diminui a distância e, consequentemente, conflitos, pois leva a práticas capazes de flexibilizar os conhecimentos e ajustá-los à realidade vivida, em um processo de constante regulagem da teoria a partir da prática, sem perder de vista os objetivos que se tem para o ensino. Ao entender a gramática como um tópico não contemplado no discurso oficial, torna-se impossível orientar-se por ele, já que a gramática, que mantém um lugar importante no ensino, precisaria ser descartada, e não redimensionada, o que foge completamente à realidade da sala de aula. Essa incompreensão gera dicotomias tais como a apontada entre texto e gramática.

Ainda que os gêneros apareçam hoje como a solução e o centro de um ensino de português de qualidade, com base em Correia (2017) encontramos fundamentos para afirmar que, tal como a gramática, eles também podem ser pedra no caminho do professor de português - e também do futuro professor -, que se vê sempre em meio a um dilema. À primeira vista, pode soar estranha tal afirmação. Se os gêneros são o que circula em todas as esferas da vida cotidiana, sendo base para toda e qualquer forma de interação humana, como podem ser um empecilho para o ensino? Como pudemos notar, o problema não está nos gêneros nem no ensino que o toma como base, assim como também não está na gramática, mas sim na maneira como são compreendidos. 


\section{Considerações finais}

Um aspecto relevante que a análise salientou foi que a maneira aplicacionista como a teoria tem sido trabalhada na universidade contribui para a separação entre o que se diz e o que se faz. Ainda que se proclame a todo instante a indissociabilidade entre teoria e prática, o olhar destinado à teoria faz com que as duas dimensões estejam, desde o princípio, separadas. As teorias são significadas por muitos entrevistados como disciplina curricular, e não como lente através da qual se enxerga o mundo e embasa ações. Assim, elas não compõem os modelos Discursivos dos entrevistados. Para que isso ocorra, a teoria precisa ser internalizada, sendo forma de apoiar a prática, mas sem que o professor esteja a todo tempo preocupado com uma coerência teórica. O professor que apenas tenta aplicar o que outras pessoas dizem sem refletir sobre o que faz não exercita a autonomia, o que denuncia os problemas de uma postura aplicacionista em relação ao saber teórico.

Quando é adotada uma visão aplicacionista, tendo como base um discurso prescritivista, o professor pensa em transposição, não adaptação do prescrito para o real. Todavia, há sempre uma distância esperada e própria da relação entre as duas dimensões. Em grande parte dos casos, a teoria é vista como domínio da universidade e, na prática da escola, significa que a teoria se perde após a formação acadêmica por não se relacionar com o trabalho. Isso ocorre porque muitos alunos não conseguem adaptá-las, já que desconhecem vários aspectos da realidade que será enfrentada ou, quando conhecem, pensam que um professor teoricamente bem formado será capaz de amenizar os problemas. A distância muito grande entre prescrito e real, ou o contato apenas com o prescrito, faz com que não consigam imaginar o funcionamento da teoria na prática. Se bem compreendida, a teoria embasa as ações e possibilita a reflexão, orientando o professor para criar, adaptar, esperançar novos caminhos. Teoria e prática devem se retroalimentar, de modo que ambas estejam presentes tanto na escola, quanto na universidade. Além disso, um contato maior com a realidade da sala de aula pelos alunos faria com que eles soubessem mais sobre o futuro ambiente de trabalho, percebendo que a teoria não será transposta tal qual. 
Sobre a percepção dos professores e futuros professores acerca da distância entre conhecimentos universitários e prática docente, fomos, em parte, surpreendidos. Esperávamos encontrar grandes diferenças nos Discursos sobre essa temática; no entanto, percebemos que, de um modo geral, os universitários têm consciência sobre ela. Contudo, por mais que a reconheçam, muitas vezes seus Discursos são contraditórios, ora atribuindo a culpa pela distância à visão utópica que acreditam haver sobre a escola na universidade, ora aos professores, que supostamente não agem conforme os conhecimentos universitários por questão de comodismo. Alguns fatores explicam a culpabilização dos docentes por parte de alguns graduandos: trata-se de uma maneira de os futuros professores não "jogarem fora" sua formação e de não desistirem da profissão antes mesmo de nela ingressarem, de manterem a esperança de que é possível fazer algo significativo enquanto professor.

No caso dos professores, mesmo criticando os discursos acadêmico e oficial em alguns momentos, em outros os tomam como parâmetro. Isso demonstra que, mesmo não sendo os únicos a definirem a identidade docente, a legitimidade desses discursos faz com que eles interfiram nessa construção, seja efetivamente embasando as ações, seja em forma de cobrança para alinharem-se em alguma medida. Essa tentativa de filiação por um sentimento de obrigatoriedade, sem que tais discursos constituam os modelos Discursivos sobre a aula de português, é prejudicial para o professor e para o ensino: ao primeiro, pelo desgaste e frustração que pode gerar; ao segundo, pelo fato de que, por ser tentativa que não se concretiza, mas que também não deixa de estar presente, o ensino fica sem direcionamento, sem referência concreta.

Apesar de termos dividido os participantes da pesquisa em dois grupos, tendo como objetivo analisar comparativamente seus Discursos, a análise desenvolvida mostrou que há uma heterogeneidade de modelos Discursivos dentro de um mesmo grupo, não sendo possível traçar padrões nítidos para os Discursos dos alunos e dos professores e transformálos em dois grupos homogêneos. É que não é o fato de ser ainda graduando ou de já atuar como professor na sala de aula, ou ainda a idade ou época de formação que predominam na constituição identitária. O indivíduo se filia em maior ou menor grau a diferentes Discursos conforme suas vivências, de forma que vai constituindo sua identidade acerca do 
que é ser professor de LP e das responsabilidades sociais que isso implica com base em modelos Discursivos advindos dos diferentes Discursos que perpassam tais vivências. $O$ sujeito ocupa, ao mesmo tempo, várias funções sociais, sendo afetado por várias ideologias. Assim, ao mesmo tempo em que é professor, é também filho, mãe/pai, irmão, amigo, e essas várias dimensões estão sempre coexistindo. Enquanto está na sala de aula, a função professor prevalece, mas não exclui ou se desvincula por completo das que exerce em outras esferas do cotidiano. Tudo isso interfere, de alguma maneira, no agir docente. Exatamente por isso, é essencial apontar não apenas para o que os docentes deveriam fazer, mas também para o que há de proveitoso em suas ações. Na medida em que a formação universitária não pode garantir a oferta de referências de ações coerentes com as teorias estudadas, inevitavelmente os graduandos tendem a tomar como modelo os professores que observaram e que tiveram no ensino básico.

\title{
DISCURSIVE-TEXTUAL GENDER AND GRAMMAR: STONES IN THE PATH OF THE PORTUGUESE TEACHER?
}

\begin{abstract}
This article discusses some aspects of the representation of the Portuguese teacher from elementary education in face of the responsibilities that are socially attributed to him based on the Discourse Analysis proposed by James Paul Gee. It is based on the analysis of semi-structured interviews of Portuguese teachers working and students of this Language course regarding the issues involved with this topic. It concludes that, in the wake of the difficulties inherent to professional practice and the theories learned, there is a considerable gap that at times tends to a tension in academic discourse, at times it brings it as essential, at other times it demonstrates a certain unpreparedness in dealing with the difference between teaching practice and the specialized universe that conducts much of the teaching profession, in a close connection with the responsibilities that society attributes to this important actor within the school institution.
\end{abstract}

KEYWORDS: Discourse Analysis; Portuguese teacher; Social responsibility.

\section{REFERÊNCIAS}

ANTUNES, I. No Meio do Caminho Tinha um Equívoco: Gramática, Tudo ou Nada. In: BAGNO, Marcos (org.). Linguística da norma. São Paulo: Loyola, 2002.

. Muito além da gramática: por um ensino de línguas sem pedras no caminho. São Paulo: Parábola Editorial, 2007. . Lingua, texto e ensino: outra escola possível. São Paulo: Parábola, 2009. 
rábola, 2014.

Gramática contextualizada: limpando "o pó das ideias simples”. São Paulo: Pa-

BEZERRA, M. A. Ensino de língua portuguesa e contextos teórico-metodológicos. In: DIONISIO, A. P.; MACHADO, A. R.; BEZERRA, M. A. (Org.). Gêneros textuais \& ensino. Rio de Janeiro: Lucerna, 2005, p. 37-46.

CORACINI, M. J. O olhar da ciência e a construção da identidade do professor de língua. In: CORACINI, M. J.; BERTOLDO, E. S. (orgs.). O desejo da teoria e a contingência da prática: discursos sobre e na sala de aula (língua materna e língua estrangeira). Campinas, SP: Mercado de Letras, 2003, p. 193-210.

CORREIA, K. C. A. "Na prática, a teoria é outra", uma análise discursiva sobre a responsabilidade social do professor de Português da Educação Básica. Dissertação (Mestrado em Letras: Teoria Literária e Crítica da Cultura), Universidade Federal de São João del-Rei (UFSJ), 2017.

COSTA VAL, M. G. A gramática do texto, no texto. Revista de Estudos Linguísticos. Belo Horizonte, v. 10, n. 2, p. 107-133, jul./dez. 2002.

FERNANDES, C. M. B. Formação de professores, ética, solidariedade e cidadania: em busca da humanidade do humano. In: SEVERINO, F. E. S. (org.). Ética e formação de professores: política, responsabilidade e autoridade em questão. São Paulo: Cortez, 2011, p. 58-77.

FREIRE, P. Pedagogia do oprimido. Rio de Janeiro: Paz e Terra, 1997.

Cartas a Cristina: reflexões sobre minha vida e minha práxis. Organização de Ana Maria Araújo Freire. Rio de Janeiro: Paz e Terra, 2013.

Vozes, 2011

; NOGUEIRA, A. Que faz̧er: Teoria e Prática em Educação Popular. Petrópolis:

GASPARINI, E. N. Entre o saber e o saber-fazer: reflexões sobre a formação do professor de língua estrangeira na universidade. Glauks, v. 13, p. 52-61, 2013.

GEE, J. P. Social Linguistics and Literacies: Ideology in Discourses. London/New York: Routledge, 1996.

- An introduction to Discourse Analysis: theory and method. London/New York: Routledge, 2005.

. Discourse Analysis: What Makes It Critical? In: ROGERS, R. (ed.). An Introduction to Critical Discourse Analysis in Education. London/New York: Routledge, 2011, p. 23-45.

GUZZO, V. As dimensões ética e política na formação docente. In: SEVERINO, F. E. S. (org.). Ética e formação de professores: política, responsabilidade e autoridade em questão. São Paulo: Cortez, 2011, p. 43-57.

MARCUSCHI, L. A. Gêneros textuais: definição e funcionalidade. In: DIONISIO, A. P.; MACHADO, A. R.; BEZERRA, M. A. (orgs.). Gêneros textuais \& ensino. Rio de Janeiro: Lucerna, 2005, p. 19-36. 
MOITA LOPES, L. P. Oficina de Linguística Aplicada: a natureza social e educacional dos processos de ensino/aprendizagem de línguas. Campinas: Mercado de Letras, 1996.

NÓVOA, A. Os Professores na Virada do Milênio: do excesso dos discursos à pobreza das práticas. Educação e Pesquisa, São Paulo, v. 25, n. 1, p. 11-20, jan./jun. 1999.

PERINI, M. A. Sofrendo a gramática. São Paulo: Ática, 2003.

POSSENTI, S. Por que (não) ensinar gramática na escola. Campinas/São Paulo: ALB, Mercado de Letras, 1996.

TARDIF, M. Saberes profissionais dos professores e conhecimentos universitários. Revista Brasileira de Educaşão. n. 13, p. 5-24, 2000.

Recebido em: 22/04/2020.

Aprovado em: 22/05/2020. 